\title{
Rural Development initiatives of Baram Community of Takukot \\ of Barpaksulikot rural municipality of Gorkha, Nepal
}

By Baram, Bhadra

$\mathrm{M} / \mathrm{S}$ Baram is pursuing $\mathrm{PhD}$ in Rural Development from Tribhuwan University can be contacted at: bhadrabaram75@gmail.com

\begin{abstract}
Rural development is process of socio economic transformation of rural people by rural people. So as the rural people Baram community of Gorkha have initiated own development interventions on different sectors of local development. Rural development is a process of action with economic, political, cultural and social dimensions. To put it differently, agricultural development is a process whereby the farmers possess modern knowledge and information. It is imperative for the farmers to have and accept the necessary technologies, innovations and knowledge for the rural development. The objective of the study is to explore the rural development initiatives on Environment, Agriculture, Tourism, Innovation, Employment, Migration, and informal economy of Baram Community of Takukot Gorkha Nepal. Methodologically 10 households were surveyed as Household questionnaire survey (HS). Purposively 1 female and 4 male ward members were selected for focus group discussion (FGD) in ward office. One ward chairperson was invited for Key Informant's Interview (KII). In conclusion Baram community is one of the dignified community of Nepal. Economically and socially their living standard is below the satisfactory line. They are marginalized people but laborious and active in rural development activities in rural municipalities. Baram communities are highly active in environment conservation, modern agriculture, rural innovation, tourism, employment generation and other informal economies.
\end{abstract}

Keywords: Baram Community, Barpaksulikot Rural Municipality, Rural Development

\section{Introduction}

Development is a multidimensional process of action, organization and communication and involves economic, political, social and cultural factors. As underlined by some of the examples from different parts of the world, it plays a vital role in the development of the rural sections in many countries. Rural Development is the management of basic necessities of life, freedom, and self-respects (Singh, 2009). People have certain basic needs; without which it would be impossible (or very difficult) for them to survive. The basic necessities include food, clothes, shelter, basic literacy, primary health care, and security of life and property. The core definition 
of development in the Human Development Reports of UNDP is 'the enlargement of people's choices' (Pieterse, 2010). The development in this sense of community upliftment and wellbeing has not approached in Baram Community. Alternative development is an alternative way of achieving development, sharing the same goals as mainstream development but using different means, participatory and people-centered.

Baram also known as Baramu, are one of the highly marginalized indigenous communities. They are scattered in different villages in Gorkha, Tanahu, Dhading, Makawanpur and Nawalparasi districts in Nepal. Although they have been immensely influenced by Hindu religion and culture, they have their own original culture and they are in fact, animists or worshipers of nature. They worship their family gods such as Chandi, Bhume, Forest gods and goddess. They have blind faith on their traditional Shaman who perform overall rituals, culture and do treat illness. Their main occupation is agriculture and animal husbandry.

They call themselves as Baram or Baramu. These two words Baram and Baramu are used interchangeably. Their ancestral domain is Gorkha district. Later on, they were migrated to other districts. They are rich in their distinct culture, religion, rituals, identity, customs and lifestyles. According to latest national census 2011, the population of Baram is 8,140. Baram have their own mother tongue called Balkura, which belongs to Tibeto-Burman language family. This language is in the verge of extinction. Even though their population is spread over 13 different district, the language of Baram, Balkura is spoken only in Takukot and Pandrung of Gorkha district. The term Balkura means, the language spoken by men. According the latest national Census of 2011, of their total 8,140, as many as 155 people only speak their mother tongue. In previous national census of 2011, the data showed that there were 350 people who could speak Balkura. Balkura is in the verge of extinction. Takukot is a Ward of Barpaksulikot Rural Municipality in Gorkha District in the Gandaki Province of northern-central Nepal.

\section{Objective}

To explore the rural development initiatives on Agriculture, Employment, Environment, Informal economy

Innovation, Migration, Tourism, of Baram Community of Takukot Gorkha Nepal

\section{Methods}

There are 215 households in the Takukot. Purposively 10 households were selected randomly 
around the ward office of Takukot ward. Head of a household was the respondent. 10 households were surveyed on each Household questionnaire survey (HS). Purposively 1 female and 4 male ward members were selected for focus group discussion (FGD) in ward office. One ward chairperson was invited for Key Informant's Interview (KII).

Table No: Data collection and sampling Tools

\begin{tabular}{|l|l|l|l|l|}
\hline Respondents & Population & Data Collection Tools & Sample Size & Sampling Tool \\
\hline Households & 215 & Household Survey (HS) & 10 & $\begin{array}{l}\text { Purposive } \\
\text { Random }\end{array}$ \\
\hline Ward Members & 5 & Focus Group Discussion (FGD) & 5 & $\begin{array}{l}\text { Purposive } \\
\text { Random }\end{array}$ \\
\hline $\begin{array}{l}\text { Ward } \\
\text { Chairpersons }\end{array}$ & 1 & $\begin{array}{l}\text { Key Informant's Interview } \\
\text { (KII) }\end{array}$ & 6 & Purposive \\
\hline
\end{tabular}

(Study, 2019)

Data Collection tools and techniques

A mixed method approach will be utilized. Quantitative data will be used to estimate the baseline values of the indicators, while qualitative information will be used to support the findings of the quantitative survey and to identify other issues that may not have surfaced during the quantitative survey. Household questionnaire survey(HS), Focus Group Discussions (FGDs) and Key Informant Interviews (KIIs) will be the major data collection methods.

Data Analysis tools and techniques

Being an empirical study the major thrust was to collect the primary data. The vast area with difficult climate and extremely inaccessible terrain of Takukot. A well-developed questionnaire (Open and close ended) an extensive was conducted. Data were tabulated and simple statistical techniques like percentage, mean, will be used to do the data analysis. The qualitative data will be analysed on the basis of analytical framework of the study. Qualitative data analysis works a little differently from quantitative data, primarily because qualitative data is made up of words, observations, images, and even symbols. Deriving absolute meaning from such data is nearly impossible; hence, it is mostly used for exploratory research. While in quantitative research there is a clear distinction between the data preparation and data analysis stage, analysis for qualitative research often begins as soon as the data is available. As it is the mixed research both qualitative and quantitative attributes are appeared. 


\section{Discussion}

Barpaksulikot Rural Municipality was established in 2017 (2073 BS) as a local government of Nepal. The headquarters of this Gaupalika is located in Takukot, Gorkha district, Gandaki Province of Nepal. Barpaksulikot is a rural municipality and also known as Gaupalika in the Nepali Language. The total area of this Municipality is $200.63 \mathrm{~km}^{2}(77.46 \mathrm{sq} \mathrm{mi})$. The total population of the municipality is according to 2011 (2068 BS) Nepal census is 25,389. Mainly Ethnic groups Gurung, Baram, Magar society are living there except that other caste Bhrahman, Kshetri, Damai, kami also living to there (Bhadra, 2019). The density of this rural municipality is $130 / \mathrm{km}^{2}$ (330/sq mi). This Rural Municipality is divided into 8 wards. Barpak, Swara, Saurpani, Takumajha Lankuribot, Takukot, Pachkhuwa Deurali and Pandurng Village Development committees (VDCs) were incorporated to form Barpak Sulikot. This Municipality came into existence in 2017 (2073 BS) (Barpaksulikot Rural Municipality, 2018).

\section{Rural Development Initiatives of Barpaksulikot Rural Municipality and Baram Community}

\begin{tabular}{|l|l|l|l|l|}
\hline SN & $\begin{array}{l}\text { Rural Development } \\
\text { Initiatives }\end{array}$ & $\begin{array}{l}\text { Total Projects of Rural } \\
\text { Municipality }\end{array}$ & $\begin{array}{l}\text { Conducted by } \\
\text { Baram }\end{array}$ & Percentage \\
\hline 2 & Agriculture & 20 & 6 & $40 \%$ \\
\hline 5 & Employment & 7 & 5 & $70 \%$ \\
\hline 1 & Environment & 17 & 5 & $40 \%$ \\
\hline 6 & Informal Economy & 35 & 20 & $60 \%$ \\
\hline 4 & Innovation & 3 & 2 & $75 \%$ \\
\hline 3 & Tourism & 18 & 8 & $45 \%$ \\
\hline & Average & 16 & 7 & \\
\hline
\end{tabular}

(Barpaksulikot Rural Municipality, 2018)

Agriculture - Agriculture is the mainstay of many countries, ensuring food security, livelihoods, export earnings and economic development. It is predominantly associated with rural areas but it has been practiced in urban and peri-urban sites for centuries. Although agriculture is, in part, responsible for environmental damage, new trends are emerging: agro-ecological practices, for instance, are less harmful to the environment, ecology and communities. For many small farmers, the situation is complicated by small-scale, political, social and environmental issues but they can find proactive ways to organize, protect their livelihoods and promote sustainable and high-return products: the "Palestine Fair Trade Association" (PFTA), for instance, is empowering farmers 
and handicraft producers through fair trade and organic agricultural training and certifications, to access lucrative external markets. As Gorkha is high hilly region of Nepal. Agriculture and Animal farming is the main source of livelihood. Barams are the indigenous people of Takukot. 95\% of Barams are related in agriculture here. Among them are leading in hill farming and some of them are actively participating in programs organized by municipality. Among 20 projects directly related with agricultural development 6 projects have been undertaken by the Baram Community. So Barams are leading the Agricultural Development Activities in the Municipality.

Employment - Youth aged 15-24 number 1.2 billion, comprise approximately 18 per cent of the global population and over half of them live in rural areas of developing countries, where unor under-employment is high. This lack of rural job prospects forces many to migrate to urban centers or abroad. Few initiatives target young people in rural areas but those that do can be very successful. In the issue of employment activities only $3 \%$ youths are partly unemployed which is significantly low among other communities.

Environment - Many rural activities both cause and are affected by environmental degradation and climate change. Nevertheless, rural communities can create alternative and sustainable ways of development: "greening the economy" offers opportunities to improve social inclusion by addressing the challenges of poverty and of lack of access to energy. For instance, "The Solar Women of Totogalpa", a co-operative of women in rural northern Nicaragua, are empowering their community with renewable energy products and services, which range from solar cookers and dryers, to the electrification of households (Yarde, Luca, Longhi, Breton, \& Victoria, 2014). Environment and climate change is a global issue and one of the most important component of sustainable development goals. Barams in Gorkha are highly conscious on the issue of global warming as they are animist love nature and environment. Among 17 projects related with environment protection and climate change, Baram people successfully conducted 5 projects in their community to conserve the environment. Thus Barams are highly conscious on environmental issues of rural development of Nepal.

Gender and development- In the case of Gender is not sex as private organ but it is a sense in mind (Badal, 2017). It is socially constructed and a result of socio-cultural influences throughout an individual's development (Schneider, 2005). Gender identity can be affected by, and is different from one society to another depending on the way the members of the society evaluate the roles of females and males. In the cases of gender issues Barams are highly sensitive. There is not any gender discrimination in the community but some influences of Brahman and Chhetri are noticeable. 
Informal economy - The "informal economy" refers to all economic activities that are not or insufficiently covered by formal arrangements, (either because they are not included in the law, or not covered because the law is not enforced in practice) (Yarde, Luca, Longhi, Breton, \& Victoria, 2014). Most informal economy workers and entrepreneurs live in rural areas but informality is also an urban issue and rural out-migrants often swell the ranks of the informal economy in urban areas and abroad. As local people are main actors of local informal economy Barams are highly involved in economic activities. Among 35 projects 20 projects are completed conducted by Baram Community leaders.

Innovation - ICTs, for instance, are expanding rapidly: telecentres, internet access and mobile phones are increasingly found in rural settings. The communication bridges built between public institutions, rural organizations and people generate the opportunities to ensure share of knowledge and experience needed for rural development (Ors, 2008). People are finding creative ways to use them to get access to and exchange information (about the weather in the case of agriculture-related activities, market prices, the political and social situation and new technologies). They also use ICTs to buy and sell products, access banking and administrative services. Communication technologies also help them find and create jobs and acquire new skills in computer work and through e-learning. Government and public-private partnerships often support rural ICTs, as in the case of the "1,000 telecentres" project, launched by Paul Barera, an entrepreneur, who has established a network of telecentres in the rural areas of Rwanda (Yarde, Luca, Longhi, Breton, \& Victoria, 2014). In the issues of ICT and Innovation Barams are in front of all other community. Among 3 projects of municipality 2 have been handled by them.

Migration - Over the last 50 years, 800 million people have moved from rural to urban areas. They move either to cities in the same country or to another country. Remittances from family members abroad supplement the income of rural households. In some origin countries, such as Senegal, migrants' remittances account for up to 70 per cent of households' earnings. Some of that money is used to start new businesses which boost local economies. However, the drain of human resources from rural areas, particularly youth, is a matter of concern(ibid.). Nepal is suffering from labor migration. Most of the youths are migrating gulf and Malesia for job. It has created local labor shortage. Although remaining Barams are satisfactorily living and working for the rural development of Nepal.

Tourism - Tourism is of growing economic importance in rural areas, with interest growing in different types of holidays away from the big cities and "sea and sand" resorts. From 2015, emerging economies will, for the first time, receive more international tourists than advanced 
economies. Eco-tourisms, (which involves responsible travel to natural areas in an environmentally and socially respectful manner), is a growing trend, currently representing about 3 to 5 per cent of global tourism. It is one of the fastest growing sectors of the tourism industry. Rural areas are therefore becoming more attractive as people discover what they have to offer. Tourism can also be a cultural tool, a way for a community to share its culture. An example of this is the "Eco-Health Farm Network" in Latvia, which supports small farmers in integrating healthy and ecological food production, cultural heritage preservation and tourism(ibid.). Nepal cannot compete with India and China in agricultural and industrial production so the optimum way of Nepalese transformation is only possible by developing Nepal as a holiday destination of entire Indian and Chinese people. Among 18 projects 8 projects are conducted by Baram community. Baram people have significant number of hotels in Takukot and also started the Homestays. So Baram are highly aware in tourism as well in the important component of rural development.

\section{Conclusion}

Baram community is one of the dignified community of Nepal. Economically and socially their living standard is below the satisfactory line. They are marginalized people but laborious and active in rural development activities in rural municipalities. Baram communities are highly active in environment conservation, modern agriculture, rural innovation, tourism, employment generation and other informal economies. Future patterns of development rural areas also means paying attention to adaptation and resilience processes, energy transition and climate change issues, and new initiatives often marked by technology and collaborative dimensions that bloom everywhere. The development and implementation of experimental, interdisciplinary and participatory research devices is in this context a crucial need even from the eye of Baram community.

\section{References}

Badal, B. (2017). Mayuree Mahal: An Empirically verified sociological novel on south Asian perspective. AMAZON: Kentueky.

Barpaksulikot Rural Municipality. (2018). Annual Progress Report. Gorkha: Barpaksulikot Rural Municipality.

Bhadra, B. (2019). Gender roles and changing pattern on Baram Community: An ethnography from Chandipurnima. Nepalese Journal of Development Studies year 2 issue 1, 13-22. 
Ors, F. (2008). The Contribution of Communication to Rural Development. Fourth International Conference on Business, Management and Economics. University of Yasar.

Pieterse, J. N. (2010). Development Theory Deconstruction and Reconstruction. London: Published in association with Theory, Culture \& Society, Nottingham Trent University and Sage Publication.

Schneider, F. G. (2005). Applied social psychology: Understanding and adressingsocial and practicle problems.Thousands Oaks. Sage Publication.

Singh, K. (2009). Rural Development: Principle, Policy and Management. New Delhi: Sage Publication.

Yarde, R., Luca, L. d., Longhi, V., Breton, L., \& Victoria, P. (2014). Reporting on Rural Issues: A Media Guide. Geneva 22, Switzerland,: International Labour Organization. 